\title{
ANÁLISE DA EXPERIÊNCIA DA RUA COMPARTILHADA, BAIRRO CIDADE PEDRA BRANCA-SC, COM BASE NOS PRINCÍPIOS DO URBANISMO SUSTENTÁVEL E NOS CRITÉRIOS DE QUALIDADE DO ESPAÇO PÚBLICO.
}

\author{
Maria Fernanda Franchi de Almeida ${ }^{1}$
}

\section{RESUMO}

Este trabalho teve como objetivo analisar a experiência da rua compartilhada localizada no bairro Cidade Pedra Branca-SC, com base no conceito Urbanismo Sustentável e nos critérios de qualidade do espaço público proposto pelo urbanista Jan Gehl. A metodologia baseou-se em revisão bibliográfica, entrevista com responsável pelo empreendimento, análise documental, visita in loco e aplicação do método de qualidade com respeito à paisagem do pedestre. Este método considera doze critérios de qualidade do espaço público, tais como: proteção ao pedestre; sensação de segurança; oportunidades para caminhar, permanecer em pé, sentar-se, ouvir e conversar, brincar e praticar atividades físicas; experiências sensoriais positivas etc. Os resultados que contribuíram com o aumento da qualidade ambiental nesse projeto foram sistematizados de modo a encontrar divergências, similaridades e pontos convergentes. De forma geral, constatou-se que o empreendimento se apropria do conceito de urbanismo sustentável, sobretudo pelo caráter da multiplicidade de usos no espaço, e atende os critérios analisados, ainda que parcialmente, principalmente os de prioridade ao pedestre a partir de uma acessibilidade maior aos serviços públicos. Contudo, trata-se de uma experiência pouco diversificada quanto à classes sociais e espacialmente isolada do seu contexto local e regional, sem conectividade com o restante do bairro e da cidade, tendo em vista um sistema ainda de baixa capilaridade e focado no transporte individual.

PALAVRAS-CHAVE: Urbanismo Sustentável. Rua Compartilhada. Cidade Pedra Branca - SC

\footnotetext{
${ }^{1}$ Graduanda em Gestão e Análise Ambiental, Universidade Federal de São Carlos, UFSCar. m.franchidealmeida@gmail.com.

${ }^{2}$ Arquiteta e urbanista, professora adjunta do Departamento de Ciências Ambientais da Universidade Federal de São Carlos - DCAm/UFSCar. renataperes@ufscar.br
} 


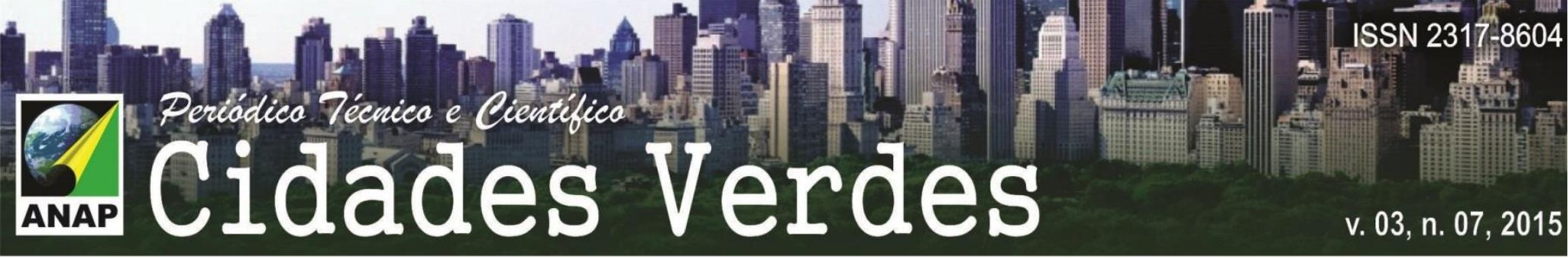

\title{
ANAL YSIS OF THE EXPERIENCE OF SHARED STREET, CITY NEIGHBORHOOD WHITE STONE-SC, BASED ON THE PRINCIPLES OF SUSTAINABLE AND THE CRITERIA FOR QUALITY OF PUBLIC SPACE PLANNING.
}

\begin{abstract}
This study aimed to analyze the experience of shared street located in the district of Cidade Pedra Branca-SC based on Sustainable Urbanism concept, and the quality criteria of public space proposed by urban planner Jan Gehl. The methodology was based on literature review, interviews with responsible for the project, document analysis, on-site visit and application of quality method in relation to pedestrian's landscape. This method considers twelve quality criteria of public space, such as: pedestrian protection; sense of security; opportunities for walking, remain standing, to sit, to listen and to talk; to play and practice physical activities; positive sensory experiences, and so on. The results that contributed to the increase of environmental quality in this project were organized in order to find divergences, similarities and convergent points. Overall, it was found that the project appropriates the concept of sustainable urban, especially in the character of the multitude of uses in space, and meets the criteria analyzed, even partially, mainly the priority to pedestrian from a greater accessibility to public services. However, it is a little diverse experience regarding to the social classes and spatially isolated from its local and regional context, without connectivity to the rest of the neighborhood and the city, towards an system with still low capillarity and focused on individual transport.
\end{abstract}

KEYWORDS: Sustainable Urbanism. Shared Street. Cidade Pedra Branca - SC.

\section{ANÁLISIS DE LA EXPERIENCIA DE COMPARTIDA DE LA CALLE, BARRIO CIUDAD BLANCA PIEDRA-SC, BASADO EN LOS PRINCIPIOS DEL DESARROLLO SOSTENIBLE Y LOS CRITERIOS DE CALIDAD DE LA PLANIFICACIÓN ESPACIO PÚBLICO.}

\section{RESUMEN}

Este trabajo tiene como objetivo analizar la experiencia de la calle compartida ubicada en el barrio Cidade Pedra Branca-SC (o Ciudad Piedra Blanca), en base con el concepto Urbanismo Sustentable y en los criterios de calidad del espacio público propuesto por el urbanista Jan Gehl. La metodología se basó en la revisión bibliográfica, entrevista con el responsable por el emprendimiento, análisis documental, visita in situ y aplicación del método de calidad con respecto al paisaje del peatón. Este método considera doce criterios de calidad del espacio público, a conocer: protección al peatón; sensación de seguridad; oportunidades para caminar, permanecer en pie, sentarse, escuchar y conversar, brincar y practicar actividades físicas; experiencias sensoriales positivas, etc. Los resultados que contribuirán con el aumento da la calidad ambiental en ese proyecto fueron sistematizados de modo a encontrar divergencias, similaridades y puntos convergentes. De manera general, se constató que el emprendimiento se apropia del concepto de urbanismo sustentable, sobre 


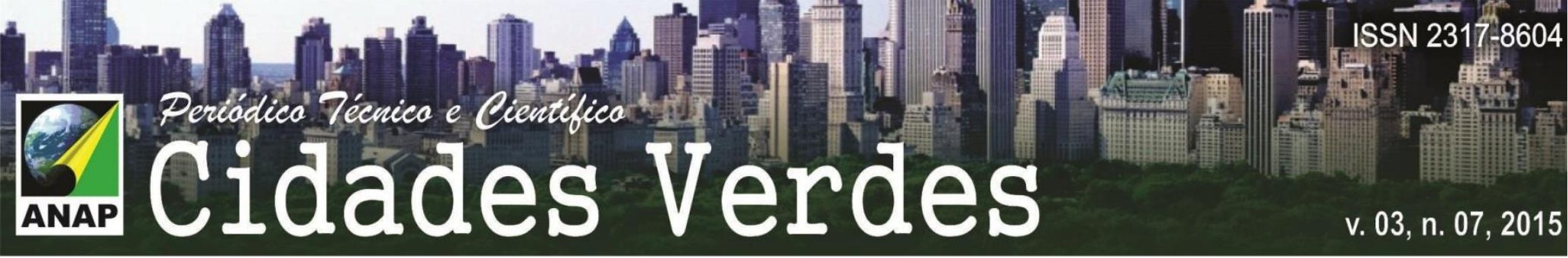

todo por el carácter de multiplicidad de usos en el espacio, y atiende a los criterios analizados, aunque parcialmente, principalmente los de prioridad al peatón a partir de una accesibilidad mayor a los servicios públicos. Todavía, se trata de una experiencia poco diversificada cuanto a las clases sociales y espacialmente aisladas de su contexto local y regional, sin conectividad con el restante del barrio y de la ciudad, teniendo en vista un sistema aun de baja capitalidad y basado en transporte individual.

PALABRAS-CLAVE: Urbanismo Sustenible. Calle Compartida. Cidade Pedra Branca - SC.

\section{INTRODUÇÃO}

Os problemas decorrentes do processo de urbanização no Brasil persistem até hoje e se propagam de forma geométrica na maioria das cidades, desde as pequenas às grandes, desenvolvidas ou não (ROSSETTO; ORTH; ROSSETTO, 2006). Contudo, o problema real não é a velocidade da urbanização ou a escala, mas sim o modo como ocorreu (MARICATO, 2003). Os impactos ambientais que ocorrem nas cidades não são simples, são influenciados pelas diferentes opções políticas e econômicas, aspectos culturais e relações interclasses. A condição social encontrada na cidade informal gera problemas ambientais e situações de risco, como desastres provocados por erosão, enchentes, deslizamentos; destruição indiscriminada de florestas e áreas protegidas; contaminação do lençol freático ou das represas de abastecimento de água; epidemias e doenças provocadas por umidade e falta de ventilação nas moradias improvisadas, ou por esgoto e águas servidas que correm a céu aberto, entre outros (GRONTEIN, 2001).

O urbanismo sustentável é uma vertente que surgiu primeiramente como Novo Urbanismo, em 1980, nos Estados Unidos. Através dele é possível buscar a longo prazo o desenvolvimento sustentável e um crescimento mais ordenado da cidade, que minimizaria os impactos sociais, ambientais e econômicos (EcoD, 2008).

Como afirmam Silva; Romero (2010), o urbanismo sustentável não é estático e está sempre se adaptando às necessidades dos seres humanos, envolvendo fatores socioculturais, econômicos, ambientais e tecnológicos. 
Os princípios fundamentais do urbanismo sustentável são: 1) prioridade ao pedestre, estimulando através de melhorias das ruas e calçadas a locomoção a pé; 2) uso misto e complementariedade, evitando longos deslocamentos; 3) diversidade de moradores, promovendo o convívio de pessoas de diferentes classes sociais; 4) senso de comunidade, reforçando a identidade local e a sensação de pertencimento; 5) densidade equilibrada, segundo este conceito a densidade ideal seria entre $400 \mathrm{a}$ 800 habitantes por hectare; 6) sustentabilidade e alta performance do ambiente construído, utilizando-se de técnicas de construção que reduzem o impacto ambiental; 7) espaços públicos atraentes e seguros, garantindo o vigor dos espaços públicos; 8) harmonia entre natureza e amenidades urbanas, melhorando a qualidade de vida dos moradores, atraindo a biodiversidade e evitando ilhas de calor; e 9) conectividade e integração regional, a cidade terá múltiplos centros que se complementam (EcoD, 2008).

Segundo Romero e Andrade (2004), os princípios para uma cidade sustentável são imprescindíveis de serem aplicados, mesmo que a região possua aspectos físicos, culturais e socioeconômicos diferenciados.

Dentro do conceito de urbanismo sustentável há a valorização do espaço público e a percepção de sua importância para a qualidade de vida nas cidades e para a interação entre os habitantes. Partindo dessa concepção, doze critérios para determinar um bom espaço público foram escritos no ano de 2006 em conjunto pelos urbanistas Jan Gehl, Lars Gemzøe e Sia Karnaes (Gehl, 2014). São eles: 1) Proteção contra o tráfego; 2) Segurança nos espaços públicos; 3) Proteção contra experiências sensoriais desagradáveis; 4) Espaços para caminhar; 5) Espaços de permanência; 6) Ter onde se sentar; 7) Possibilidade de observar; 8) Oportunidade de conversar; 9) Locais para se exercitar; 10) Escala humana; 11) Possibilidade de aproveitar o clima; e 12) Boa experiência sensorial.

Em “Cidade Para Pessoas” (Gehl, 2014) Jan Gehl aborda alguns princípios do urbanismo sustentável através da dimensão humana, um ponto do planejamento urbano que vem sendo apagado durante o desenvolvimento das cidades: os pedestres não têm mobilidade e os sentidos humanos são deixados de lado. Nossos sentidos são desenvolvidos para a compreensão no plano horizontal e daí a 
importância também da escala ao nível dos olhos, para que seja proporcionada uma experiência sensorial agradável ao transeunte. Para que a cidade seja segura, sustentável e saudável, o espaço público tem que exalar vida e ser convidativo, sendo utilizado por diferentes pessoas e grupos.

Um exemplo brasileiro de tentativa de concretização dos nove princípios de urbanismo sustentável e de bons espaços públicos é o bairro Cidade Pedra Branca, localizado no município de Palhoça, Santa Catarina. Este projeto surgiu a partir do planejamento de transformar uma fazenda em um bairro, tendo como elemento propulsor a Universidade do Sul de Santa Catarina, que foi instalada no local. O Cidade Pedra Branca possibilita aos seus moradores a opção de morar, estudar, trabalhar e buscar lazer no mesmo local, evitando grandes deslocamentos, incentivando o caminhar e proporcionando encontro e interação.

Este exemplo citado é muito recente e também pouco estudado, necessitando ser melhor compreendido do ponto de vista científico, já que pode servir como ponto de partida para outros bairros e cidades buscarem iniciativas mais sustentáveis, em termos ambientais e sociais.

\section{OBJETIVOS}

O objetivo geral do trabalho foi analisar a experiência da Rua Compartilhada do bairro Cidade Branca, Palhoça-SC, com base no conceito de Urbanismo Sustentável e nos critérios de qualidade do espaço público proposto pelo urbanista Jan Gehl. Como objetivos específicos, tivemos 1) estudar os conceitos de Urbanismo Sustentável; 2) aplicar o método de qualidade com respeito à paisagem do pedestre proposto por Jan Gehl no Passeio Cidade Pedra Branca; e 3) sistematizar as ações e os resultados que contribuíram com o aumento da qualidade ambiental nesse projeto, buscando encontrar divergências, similaridades e pontos convergentes com os doze critérios para determinar um bom espaço público. 


\section{METODOLOGIA}

A metodologia desta pesquisa fundamentou-se em revisão bibliográfica, revisão documental, assim como na análise prática, por meio de um estudo de caso, entrevista e visita in loco.

A revisão bibliográfica consistiu-se na pesquisa desenvolvida a partir de material já publicado, principalmente livros, artigos científicos e publicações periódicas (jornais e revistas) sobre o tema. A revisão documental consistiu, sobretudo, na análise dos documentos relativos ao projeto Cidade Pedra Branca.

Como estudo de caso, foi selecionado e analisado o Projeto Pedra Branca, Palhoça - SC. Os critérios para a escolha desse bairro justificaram-se por ser um dos primeiros bairros brasileiros a buscar tais conceitos, além de ser acessível para a obtenção de dados. Com a finalidade de se obter uma visão mais detalhada dos projetos desenvolvidos, foi realizada uma entrevista com um dos coordenadores do Projeto Pedra Branca.

Também foi feita uma visita ao local, com foco na Rua Compartilhada, para aplicar os conceitos compilados em uma tabela baseada no livro "Cidade para as pessoas", de Jan Gehl. Por meio dessa análise prática procurou-se obter uma visão mais ampla a respeito dos projetos sustentáveis aplicado nesse local.

Os doze critérios analisados para a Rua Compartilhada para se determinar um bom espaço público foram: 1) proteção contra o tráfego e acidentes - sensação de segurança; 2) proteção contra o crime e a violência - sensação de segurança; 3) proteção contra experiências sensoriais desconfortáveis; 4) oportunidades para caminhar; 5) oportunidades para permanecer em pé; 6) oportunidades para sentarse; 7) oportunidades para ver; 8) oportunidades para ouvir e conversar; 9) oportunidades para brincar e praticar atividade física; 10) oportunidades de aproveitar os aspectos positivos do clima; 11) experiências sensoriais positivas; 12) escala.

Após esse processo de pesquisa e coleta de dados, os resultados foram compilados, sistematizados e discutidos tendo em vista o alcance dos objetivos propostos. 


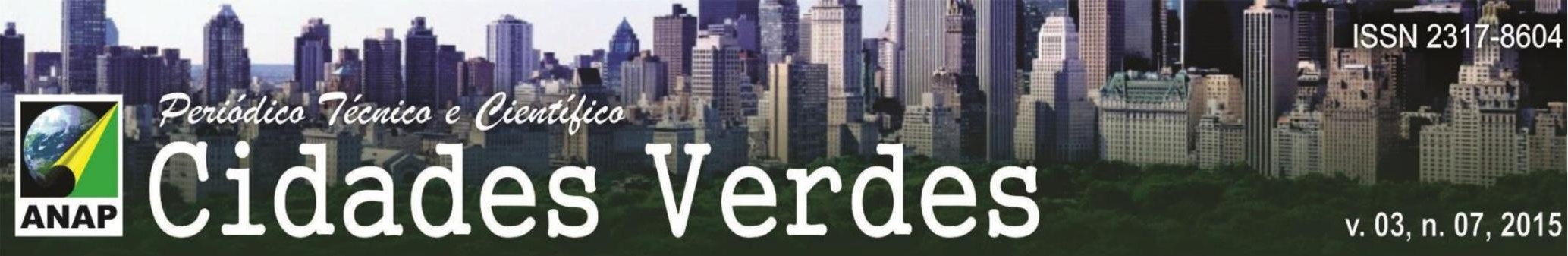

\section{RESULTADOS}

O bairro Cidade Pedra Branca, localizado em Palhoça/SC vem sendo reconhecido e mencionado por sua recente experiência com conceitos do urbanismo sustentável. Contudo, no geral, o bairro possui residências de classe média alta e as ruas são comuns, muitas delas com iluminação insuficiente, sem calçada e com nenhuma política de preferência ao pedestre. São caminhos que desestimulam o deslocamento à pé, com carros andando rapidamente e sem faixas de pedestres, além dos obstáculos citados anteriormente.

Os critérios analisados foram aplicados principalmente em uma rua, chamada "Passeio Pedra Branca", que é uma rua compartilhada e tem função de ponto turístico. Quando acessa-se o "Passeio Pedra Branca" há um portal marcando seu início e a partir dele muda-se o aspecto do restante do bairro.

A tabela a seguir apresenta os critérios que foram analisados na experiência da Rua Compartilhada do bairro Cidade Branca, Palhoça-SC.

Tabela 1: A CIDADE AO NÍVEL DOS OLHOS: DOZE CRITÉRIOS DE QUALIDADE

\begin{tabular}{|c|c|c|c|c|c|c|}
\hline \multicolumn{2}{|c|}{ ESPAÇO PÚBLICO } & & & & & \\
\hline & Localização & \multicolumn{5}{|c|}{ Passeio Pedra Branca, Palhoça, Santa Catarina - Brasil } \\
\hline & CRITÉRIOS & $\begin{array}{l}\text { ASPECTOS A } \\
\text { SEREM } \\
\text { OBSERVADOS }\end{array}$ & SIM & PARCIAL & NÃO & $\begin{array}{c}\text { DESCRIÇÃO } \\
\text { QUALITATIVA }\end{array}$ \\
\hline \multirow[t]{3}{*}{$=(d)$} & \multirow{3}{*}{$\begin{array}{l}\text { 1. PROTEÇÃO } \\
\text { CONTRA O TRÁFEGO } \\
\text { E ACIDENTES - } \\
\text { SENSAÇÃO DE } \\
\text { SEGURANÇA }\end{array}$} & $\begin{array}{l}\text { Equipamentos de } \\
\text { proteção aos } \\
\text { pedestres (guias, } \\
\text { guarda-corpos). }\end{array}$ & $\mathrm{X}$ & & & \\
\hline & & $\begin{array}{l}\text { Sinalização } \\
\text { direcionada ao } \\
\text { pedestre. }\end{array}$ & & $\mathrm{X}$ & & \\
\hline & & $\begin{array}{l}\text { Orientação ao } \\
\text { ciclista. }\end{array}$ & & $\mathrm{X}$ & & \\
\hline
\end{tabular}




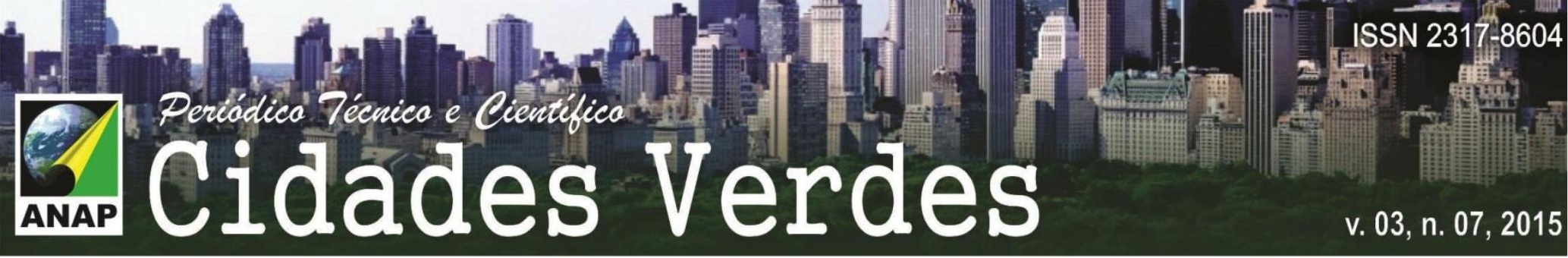

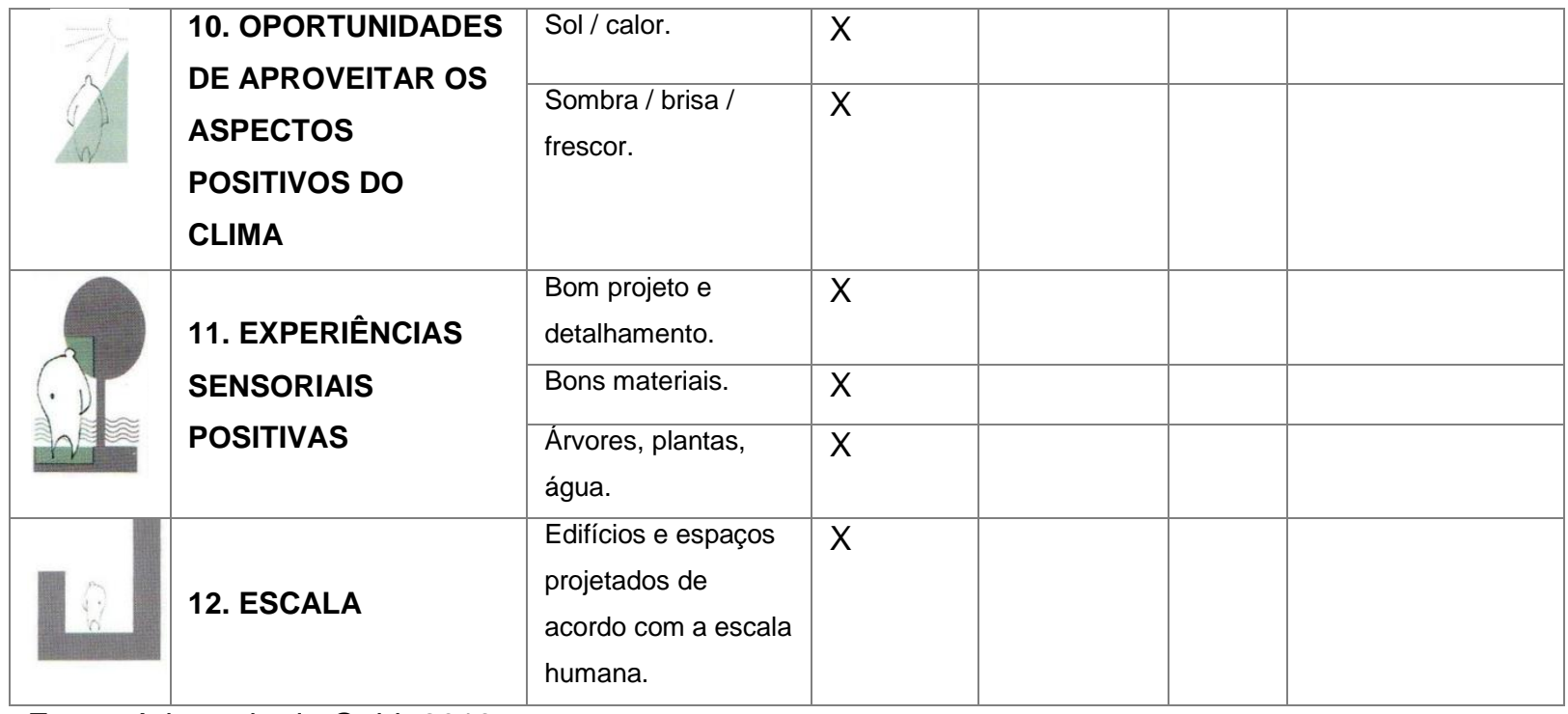

Fonte: Adaptado de Gehl, 2013.

De forma geral, verificou-se que os critérios são atendidos, ainda que parcialmente. Há a sensação de segurança para caminhar, não há obstáculos, a rua é no mesmo nível que a calçada, propiciando um ambiente para andar de bicicleta, patins, skate, etc. As atividades são sobrepostas, a rua tem vida durante o dia e à noite, sendo que ao escurecer, o pedestre conta com um espaço bem iluminado e seguro.

Durante toda a extensão da rua a construção é atrativa e há cobertura, permitindo que as pessoas se protejam de experiências sensoriais desconfortáveis, como a chuva e o vento. Também há espaços convidativos, tanto para permanecer em pé, quanto para sentar-se. Estes locais proporcionam a interação entre as pessoas, permitindo também um aproveitamento do clima.

Há calçadas por todo o trajeto, elas são largas, planas e no mesmo nível da rua. Faixas de pedestres e guarda-corpos promovem a sensação de segurança para andar a pé, sempre priorizando o caminhar. Além disso, o pedestre encontra uma grande diversidade de lugares para permanecer sentado, em pé ou conversando com outras pessoas, como um grande número de bancos, alguns de frente ao outro e instalados em locais agradáveis. 
Um aspecto que poderia ser melhor aproveitado é a orientação aos ciclistas, pois há somente uma pequena sinalização no início da rua, mas não há uma ciclovia delimitada no restante do caminho.

A iluminação também é muito boa em toda sua extensão da rua compartilhada, quando anoitece o número de pessoas circulando aumenta, ao contrário do restante do bairro, que é mais movimentado na parte da tarde. Seguranças também são vistos somente no Passeio, assim como câmeras de monitoramento. Há lojas diversas, algumas funcionam somente durante o dia, e outras, como bares e restaurantes, funcionam somente à noite. Percebe-se que a maior parte do público que frequenta o Passeio, tem elevado poder aquisitivo, não é um ponto turístico que abrange toda a comunidade de Palhoça.

Conforme percorre-se o Passeio, é agradável observar as vitrines das lojas, a beleza das construções e a boa qualidade dos materiais empregados na construção do espaço. Porém, mais uma vez, a impressão é de que somente uma população bem sucedida poderá aproveitar as opções de lazer e distração ali ofertadas. Aspectos que poderiam ser aproveitados por qualquer pessoa que visitasse o local seriam as oportunidades para brincar e aproveitar o clima, contando com a proteção de aspectos climáticos negativos, como a chuva.

Um aspecto evidenciado foi a "escala", já que todos os prédios foram construídos com fachadas "ativas" diferentes umas das outras, prendem o olhar e fogem do monótono. Todas as lojas interagem com a rua, no sentido de possuírem mesas na calçada, vidraças onde quem está do lado de dentro pode observar quem está passando do lado de fora e vice-versa.

A questão da valorização do pedestre também é evidenciada. No geral, o pedestre sente que está em um local que foi planejado para ele transitar livremente, sem obstáculos ou priorização de automóveis, é experimentada a sensação de estar em uma cidade construída para pessoas.

Observa-se que a Rua Compartilhada é como se fosse um embrião do urbanismo sustentável. Contudo, pelo menos alguns de seus conceitos poderiam futuramente ser aplicados no restante do bairro ou então a rua se tornaria somente um ponto turístico, como se fosse um "parque temático". 
Nesse sentido, é pertinente o questionamento feito por Silva; Ávila (2014, p.46), "o bairro Cidade Pedra Branca é sustentável ou somente uma jogada de marketing do mercado imobiliário"?

Apesar de uma suposta proposta de funcionar como local de lazer para toda a população da cidade Palhoça-SC, que conta com poucas opções de lazer, o público alvo é a classe média alta, público este que terá condições financeiras de adquirir um imóvel no local e consumir nas lojas ali localizadas.

O Passeio Pedra Branca trouxe para o Brasil uma Rua Compartilhada que contêm conceitos muitas vezes vistos somente em países de primeiro mundo e por isso, está servindo como exemplo para novos empreendimentos, inclusive tem recebido visitas de profissionais do Brasil e de outros países. Uma rua como esta é cara e difícil de ser implementada, porém se somente alguns critérios ali implementados fossem seguidos em outros locais (inclusive no próprio bairro), como a prioridade ao pedestre, já seria uma mudança positiva.

Conclui-se que a maioria dos critérios foram muito bem abordados, mas alguns poderiam ser melhoras e o aspecto social necessita receber uma atenção maior, para que um exemplo inovador em sustentabilidade não torne-se somente uma jogada de marketing.

Nas imagens das figuras 1, 2, 3, 4, 5 e 6 abaixo, é possível ver como alguns destes conceitos são aplicados na Rua Compartilhada. 
espaços para sentar, monótonas, inseguras e sem estrutura adequada para o pedestre.

O urbanismo sustentável tem se tornado uma pauta importante para as cidades, porém muitas vezes é utilizada como estratégia de marketing. A maioria destes empreendimentos são voltados para um público de classe média alta, deixando de lado uma grande parcela da população do país.

Conclui-se que a maioria dos critérios foram muito bem abordados, mas alguns poderiam ser melhorados e a o aspecto social necessita receber uma atenção maior, para que um exemplo inovador em sustentabilidade não torne-se somente uma jogada de marketing.

A sustentabilidade está baseada em um tripé, que engloba o Econômico, Social e o Ambiental (SILVA; ÁVILA, 2014). Portanto, deve-se dar importância à comunidade do entorno e do município. Uma rede de transporte público que possibilitasse o acesso de munícipes de áreas distantes seria um primeiro passo para aumentar a acessibilidade e para diversificar o público. Além disso, como proposto por Jan Gehl (2013), uma cidade que propõe-se a se transformar em uma "Cidade para pessoas" deve manter a rua viva, oferecendo diversas atividades culturais e de lazer para toda população.

O Pedra Branca instiga sérios questionamentos à respeito da conectividade de transporte, tendo em vista um sistema de baixa capilaridade e dependente do modal rodoviário. Do mesmo modo, retorna-se à subjetividade dos aspectos da diversidade de moradores, reforçando a tendência da formação de guetos de elite (RIBEIRO, 2014).

Os princípios do urbanismo sustentável não devem ser utilizados apenas para um público de alta renda ou para alavancar vendas. Devem estar atrelados a políticas habitacionais de maior abrangência e conectadas com o desenho e com o planejamento urbano de nossas cidades. 
